\title{
The Chinese Students' Digital Competencies Formation in the Educational Space of the Russian University
}

\author{
E.A. Belyaeva 1,2
}

${ }^{1}$ Ural State Mining University, Yekaterinburg, Russian Federation

${ }^{2}$ Ural Federal University named after the first President of Russia B. N. Yeltsin, Yekaterinburg, Russian Federation

\section{Abstract}

In the past two decades, in the context of internationalization of higher education, the formation of a digital society in Russia and overseas the requirements for higher education have changed significantly. Digital skills and competencies should be acquired by a person in the education system, so the role of higher education and learning in general is growing. The Chinese students' influx to the Russian universities is increasing, which presents a challenge for the Russian universities to develop the

Corresponding Author:

E.A. Belyaeva

ekaterina.podergina@mail.ru

Published: 21 January 2021

Publishing services provided by Knowledge E

(c) E.A. Belyaeva. This article is distributed under the terms of the Creative Commons

Attribution License, which permits unrestricted use and redistribution provided that the original author and source are credited.

Selection and Peer-review under the responsibility of the XXIII International Conference Conference Committee. digital skills of the Chinese students demanded on the global labor market. The main objectives of the study were to determine the basic digital competencies that Chinese students need to form in the process of training at the Russian higher school. The study was conducted at three universities in Yekaterinburg. The research methodology combined both qualitative and quantitative approaches. The primary data was collected using questionnaires and in-depth interviews. 500 Russian and 500 Chinese students were questioned on the basis of quota sampling. In-depth interviews with 50 experts were conducted. The study has revealed the basic digital competencies required by Chinese students. They include: the ability to quickly respond to the intensification of ICT development, the ability to independently master and create innovations, the ability to work in network organizations with a decentralized management system (including Russian-Chinese), the skill of continuous self-education, the skill of self-study situation analysis and the skills of operational decision making. The research has found that in modern Russia there is a need to coordinate interstate, regional and university levels of innovative educational cooperation between Russia and China, to train Russian highly qualified specialists for the implementation of bilateral digital educational cooperation and to increase the financial component of the innovative development of the Russian-Chinese educational cooperation.

Keywords: digitalization of higher education, digital competencies, Chinese students, the educational space of the Russian university, the interaction of the Russian and the Chinese higher schools. 


\section{Introduction}

In the past two decades, in the context of globalization, internationalization of higher education, technological and organizational changes, the formation of a digital society in Russia, the requirements for higher education have changed significantly. Digital skills and competencies should be acquired by a person in the education system, where the main attention should be paid to the content and training methods to provide future specialists with the skills of the 21st century [1]. The innovative and educational potential of Russian higher education is often insufficient for harmonious integration into the global educational space, and the insufficient digitalization of universities in some aspects determines low competitiveness compared with leading world universities.

In the last few years one can see cardinal changes in the geopolitical configuration of the world where China occupies one of the leading positions. Today China is ahead of a lot of other countries in digital development, including Russia. In spite of the active development of cooperation between Russia and China in the field of higher education (intensive increase in the number of student exchanges; development of academic mobility; deep diversification of types and directions of Russian-Chinese joint projects in the field of higher education; creation of joint educational organizations; continuous growth in the number of implemented joint educational programs etc.) the basis for bridging the digital divide between the two partner countries is created. The Chinese students' influx to the Russian universities is constantly increasing, which presents a challenge for the Russian universities to develop Chinese students' digital skills demanded on the global labor market.

When analyzing the digital competencies required by Chinese students, it is necessary to consider the changing requirements for higher education, which are caused by the process of internationalization of higher education and the intensification of information and communication technologies (ICT) development, which widen the digital divide [2], [3]. Today, representatives of the $\mathbf{Z}$ generation predominantly study at the higher school. Sapa A.V., Stillman D. distinguish some features of the $Z$ generation. This generation is characterized by the fact that the virtual and real worlds are the same ones; personalization takes place in a virtual space. Generation Z is moving from interactions to "transactions". It is pragmatic about education and job choice; it constantly strives forward and experiences an existential sense of their own digital backwardness. Generation Z is also characterized by a do-it-yourself social feeling, instilled in the practice of You-tube channels (search for their own solutions, avoiding traditional everyday practices) and a high self-motivation for learning and career 
progress [4], [5], [6]. At the same time, generation $X$ faculty staff with low digital activity mainly works in the Russian higher school, it is difficult for them to establish effective educational communication with generation $\mathrm{Z}$ and to form students' digital skills. Recent studies note changes in the competencies of university graduates that are in demand on the labor market. The majority of them talks about digital competencies [1], [7], [8], [9], [10], [11] etc. In a twenty-year retrospective, employers wanted to get a specialist with a specific set of knowledge, skills and abilities ("hard" competencies) obtained in higher school. Today, "soft" competencies (the ability to adapt, retrain quickly and to respond quickly, etc.) are becoming more demanded on the labor market [5], [6]. According to Burlakova I.I. it is due to the requirements of the labor market in specialists, not so much owning a set of specific skills, as in easily trained and able to constantly master the changing professional activities [12].

In the past decade, China's economy and its digitalization have been actively developing. The policy "Made in China - 2025" is focused on achieving digital and technological superiority over the countries of the West and the USA. According to official statistics, the number of Chinese students is increasing every year (2.5 times a year over the past 10 years) at Russian universities [13]. Therefore, the task of Russian universities is to train competitive Chinese graduates for the global labor market.

The problem of the digital divide elimination between Russian and Chinese students is complemented by difficulties in the sociocultural dialogue between the host Russian university and Chinese students, which is reflected in Russian and Chinese studies. One of the leading causes of problems in the digital interaction between Chinese and Russian students is the mismatch between Chinese and host cultures. Russian scholars V.V. Malyavin and A.A. Maslov [14] consider various aspects of the interaction between Russia and China, highlighting the worldview, religious and political components. The works of Kalita V.V. [15], Vinichuka N.V. [15], Popkova EB [16], Raspertova [17] are devoted to the problems of enculturation and ideological contradictions of Chinese students at Russian universities. The works of Grebennikova I.A. [18], Danilenko O.I., Li Ts., Xu I. [19], Dementieva S.V. [20], and others consider the problem of adaptation and socialization of Chinese students at Russian universities as the main problem field of interaction between Russians and Chinese.

Although the problems of the competency-based approach implementation and the processes of inculturation and training of Chinese students at Russian universities have already been studied rather extensively. To the best of our knowledge, the formation of "soft" digital competencies of Chinese students in a Russian university still remain to be revealed, the purpose of the present work was to analyze this issue in detail. 


\section{Methodology and Methods}

The main objectives of the study were to determine the main "soft" digital competencies that Chinese students need to form in the process of training at Russian universities, assess the ability of Russian universities to form them, and identify the factors that prevent the digitalization of Russian higher education.

The research methodology combined both quantitative and qualitative approaches. The primary data was collected using questionnaires and in-depth interviews. 500 Chinese and 500 Russian students (studying or living with Chinese) were questioned on the basis of quota sampling. There are $57 \%$ boys and $43 \%$ girls. According to the age of the respondents, the sample was quite homogeneous: the majority of the respondents are between the ages of 19-24. In-depth interviews (50) were conducted with Chinese specialists trained at a Russian university on the issues referring to demanded digital competencies in their daily and professional lives.

When interpreting the research data, a comparative and level analysis of the results as well as statistical methods (a method of descriptive statistics and t-criterion Student's test) were used. Factor analysis was used to identify the main factors holding back the development of digital competencies among Chinese students and widening the digital divide.

The study was conducted in three Russian Universities in Yekaterinburg, Russia.

Procedure. Qualitative research: in-depth interviews. An exploratory pilot study with informants (50 120-minutes in-depth interviews) was conducted. Former Chinese students who had been trained at Russian universities were defined as informants. The respondents were asked questions relevant to the aim of the study in order to determine the main digital competences used in their professional and everyday life and those of which that were demanded on global labor market.

Quantitative research: questionnaire survey. The aim of the questionnaire survey was to analyze Chinese and Russian students' competences they obtain when training at Russian universities. The quantitative stage was conducted using a questionnaire survey. The questionnaire used in the study was formulated as a result of the in-depth interviews with informants described above. The survey questionnaire consisted of 56 questions. 


\section{Results and Discussion}

Our study has shown that at the initial stage of training, Chinese students are characterized by an average level of information-analytical component (understanding the need to develop digital competencies) $(M=28.4)$, which are in demand on the global labor market; the motivational-evaluative component $(M=28.7)$, which reflects the degree of importance of digitalization in everyday and professional life, and the sociocommunicative component $(M=29.3)$, which reflects digital communication skills. A low level was revealed in relation to the joint digital interaction of Russian and Chinese students, reflecting the desire for digital communication with representatives of other cultures ( $M=26.1)$. The study has shown a digital divide in the interaction of Chinese and Russian students at the initial stages of training at Russian universities. It indicates that Chinese students entering Russian universities do not understand what kind of digital competencies they will master in the learning process. They also do not know what kind of digital competences will be demanded in their future professional activities. It should be noted that Chinese students have no practice of interacting with Russian students and faculty staff in instant messengers, social networks, which complicates the process of inculturation in the space of the Russian university.

At the stage of graduation from Russian universities, the attitude of Chinese to digitalization is changing and the need for obtaining "soft" digital competencies in the learning process at Russian universities is growing. The fourth year Chinese students, unlike the freshmen or the second-year students, according to statistical analysis using Student's t-criterion, have statistically significant high indicators of the need for digital skills: information and analytical component $(M=33.5 ; t=4,2, p<0.01)$; motivationalevaluative component $(M=33.7 ; t=4.8, p<0.01)$; socio-communicative component $(M$ $=32.7 ; \mathrm{t}=5.9, \mathrm{p}<0.01)$; joint digital interaction $(\mathrm{M}=32.4 ; \mathrm{t}=7.7, \mathrm{p}<0.01)$. Thus, in the process of studying at a Russian university, Chinese students begin to experience a widening digital divide. The Chinese freshmen entering the Russian university, do not attach much importance to the low digitalization of the Russian university. In addition, Russian and Chinese students see differences in the necessary digital competencies formed at the university. It is the digital divide, in fact, that leads to all the other differences called by students in relation to education and employment. Therefore, to successfully build the educational process, it is necessary, first of all, to use ICT. By the fourth year, Chinese students are more interested in developing precisely the "soft" digital competencies that will be in demand in their future professional activities. Chinese students begin to understand that digital competencies are not being formed 
enough at the Russian university (71\% of respondents) and they start to build new educational paths (13\% plan to continue their studies in China, $17 \%$ in other countries). This fact confirms the need for the formation of digital competencies among Chinese students in the space of the Russian university.

In-depth interviews with Chinese specialists allowed us to formulate the main "soft" digital competencies that need to be developed by Chinese students during their training at the Russian universities. These are the most demanded competencies in students' future professional activities according to Chinese experts who graduated from the Russian universities. According to the Chinese, the most demanded competencies are: the ability to quickly respond to the intensification of ICT development, the ability to independently master and create innovations, the skills of continuous bridging the digital divide, the ability to work in network organizations with a decentralized management system (including Russian-Chinese), the skill of continuous self-education, the skill of self-analysis of situations and operational decision-making.

The list of identified competencies as well as their statistical significance, allows us to agree with D. Stillman's opinion that for the generation $Z$ it is important: quick response to ICT development, life in constantly bridging the digital divide, as well as developed initiative and self-motivation to master digital reality [5]. Our research confirms the research of A. Korzhuyev [10], Popkova V.A. [16], which concludes that there is an increase in demand for "soft" competencies and a decrease in demand for "hard" competencies among university graduates on the labor market.

The study has identified the following factors that prevent the development of digital competencies among Chinese students and widen the digital divide: insufficient number of Russian-Chinese innovative educational projects ( $24 \%$ of the respondents), difficulties in coordinating the digital educational interaction of partner countries ( $21 \%$ of the respondents), insufficient innovativeness of Russian higher education (15\% of the respondents), low technical equipment of Russian universities (15\% of the respondents), lack of digital competence of Russian faculty staff (14\% of the respondents), inadequate use of ICT in the process of inculturation of Chinese students in the Russian universities (11\% of the respondents) and inadequate use of ICT in educational communicative practices (10\% of the respondents). The influence of these factors was confirmed by experts, who also agree that in modern society the demand for "soft" competencies is growing (34 statements), digital competencies are most demanding (29 statements), the modern global labor market has specific requirements for the development of digital competencies in higher education (41 statements), there are significant factors (listed 
above) that impede the development of digital competencies among Chinese students (38 statements).

Our study has confirmed the results of other researchers. The most significant factor, according to our respondents, is the insufficient number of Russian-Chinese innovative educational projects ( $24 \%$ of the respondents). According to research by Wang $\mathrm{Li}$ and Baranova I.I. 116 projects for undergraduate programs, 2 projects for master's programs, 5 projects for special courses between Russia and China are being implemented. With regard to the geography of ongoing projects, most partnership projects are carried out with universities in Heilongjiang (84 projects) and Jilin (11 projects). The majority programs with Chinese partners are implemented in the western part of the Russian Federation ( 28 programs) and 3 programs - in the central part. 9 programs began to be implemented in the southern part of Russia, 16 programs were implemented in the Siberian region and 60 programs - in the Far East [21]. It should be noted that it is necessary to expand the geography of the implementation of innovative educational projects. Promising plans for cooperation in the framework of joint educational programs should be the increase in the number of master's degree programs in computer and engineering areas of training. Active interaction between educational institutions should be accompanied by differentiation of Russian and Chinese universities by profile and, at the same time, integration into inter-university associations.

Chinese students and experts named the next significant factor - "difficulties in coordinating the digital educational interaction of partner countries" ( $21 \%$ of the respondents). At present, it is necessary to more actively involve the state in developing a strategy to strengthen Russia's position on the educational market of the Asia-Pacific region, and China, in particular, to determine the digital potential of our country as a provider of educational services and to develop a program of priorities.

According to the Export Education Services Concept of the Russian Federation, for the period 2011-2020, the coordination of digital educational interaction between Russia and China is carried out by a single interdepartmental body - a specially created government commission. It must restore the macro-regulatory functions of the state in the process of partner countries universities digital cooperation and combine efforts of the state, universities, scientific institutions and public organizations. Its task is to conduct a systematic analysis of the information received from universities, educational organizations and scientists from different fields of science [23].

Chinese students also identified the lack of innovation of Russian higher education (15\%) and the low technical equipment of Russian universities (15\%) as significant factors. 
Unfortunately, in Russia over the past five years, there has been a decrease in investment in ICT development. The OECD Research and Innovation Center (Organization for Economic Co-operation and Development) has invariably noted a decrease in the level of annual financing of innovative activities of Russian universities over the past 5 years [22]. It should be noted that this factor hinders the digitalization of higher education development and reduces the intellectual potential of Russian higher education.

The respondents also identified factors of insufficient digital competence of faculty staff (14\%), insufficient use of ICT in the process of inculturation of Chinese students at Russian universities (11\%) and insufficient use of ICT in educational communicative practices (10\%). These factors are partly confirmed by the study of Danilenko O. I., Li Ts., Xu I. [19], Popkova EB [16]. We agree with the opinion of researchers that in Russian higher schools there is a low professional competence of faculty staff (poor knowledge of foreign languages, lack of understanding of Chinese culture) working with Chinese students.

We believe that our findings are promising and should be validated using a larger sample. Further investigation should be devoted to a comparative analysis of the digital competences obtained by Russian and Chinese students at Russians and Chinese Universities.

\section{Conclusions}

Our study has identified the demand for the development of digital competencies among Chinese students being trained in Russian higher education institutions. They include: the ability to quickly respond to the intensification of ICT development, the ability to independently master and create innovations, the skills of continuously bridging the digital divide, the ability to work in network organizations with a decentralized management system (including Russian-Chinese), the skill of continuous self-education, the skill of self-study situation analysis and operational decision making.

The following factors preventing the development of digital competencies among Chinese students and widening the digital divide were identified: insufficient number of Russian-Chinese innovative educational projects, difficulties in coordinating the digital educational interaction of partner countries, insufficient innovation of Russian higher education, low technical equipment of Russian universities, insufficient of faculty staff digital competence at Russian universities, the insufficient use of ICT in the process of inculturation their students at Russian universities and insufficient use of ICT in educational communication practices. 
Our research has shown that Russia should train its own highly qualified personnel for the implementation of bilateral digital educational cooperation at the universities level (university staff, contract supervisors), and at all levels administrative staff (government organizations, state government agencies, educational institutions, research organizations, enterprises). It should be noted, that it is also necessary to increase the financial component of the innovative development of Russian higher education and RussianChinese educational cooperation, involving various sources (including the (SCO) The Shanghai Cooperation Organization countries). It is also necessary to approach this issue comprehensively, using the entire administrative potential of the government and regional authorities, developing organizations and research centers, international contacts of universities; to support and stimulate regional cooperation in the field of education and digitalization, creating territorially new Russian-Chinese scientific and educational centers.

The survey has elucidated that it is also necessary to support and stimulate regional cooperation in the field of education and digitalization, creating territorially new RussianChinese scientific and educational centers.

\section{Acknowledgments}

The authors of the article would like to thank Russians and Chinese Universities for the opportunity to conduct a sociological study.

\section{References}

[1] Voogt, J., et al. (2013). Challenges to Learning and Schooling in the Digital Networked World of the $21^{\text {st }}$ Century. Journal of Computer Assisted Learning, vol. 29, issue 5, pp. 46

[2] Dendeva, B. (Ed.). (2013). Information and Communication Technologies in Education: Monograph. Moscow: UNESCO IITE, p. 320.

[3] Klochkova, E. N. and Sadovnikova, N. A (2010). The Transformation of Education in the Context of Digitalization. Open Education, vol. 23, issue 4, pp. 13-22.

[4] Sapa, A. V. (2014). Generation Z - Generation of the GEF Era. Innovative Projects and Programs in Education, issue 2, pp. 23-45.

[5] Stillman, D. and Stillman, I. (2018). Generation Z at Work. How to Understand him and how to find a Common Language with him. Moscow: Mann, Ivanov and Ferber, p. 272. 
[6] Cummings, J. N., Sproull, L. and Kiesler, S. B. (2002). Beyond Hearing: Where the Real-World and Online Support Meet. Group Dynamics: Theory, Research, and Practice, vol. 6, issue 1, p. 78.

[7] Heye, D. (2006). Creativity and Innovation: Two Key Characteristics of the Successful $21^{\text {st }}$ Century Information Professional. Business Information Review, vol. 23, issue 4, pp. 121-122.

[8] Binkley, M., et al. (2012). Defining Twenty-First Century Skills. In P. Griffin, B. McGaw and E. Care (Eds.). Assessment and Teaching of 21st Century Skills: Methods and Approach. Dordrecht: Springer, pp. 17 e66.

[9] Quieng, M. C., Lim, P. P. and Lucas, M. R. D. (2015). $21^{\text {st }}$ Century-Based Soft Skills: Spotlight on Non- Cognitive Skills in a Cognitive-Laden Dentistry Program. European Journal of Contemporary Education, vol. 11, issue 1, p. 72e81.

[10] Korzhuyev, A. V. (2003). Traditions and Innovations in Higher Professional Education. In Korzhuyev, A. V. and Popkov, V. A. (Eds.). Electron. Text Data. Moscow: Moscow State University, p. 304.

[11] Vedyashkin, M. V., et al. (2017). Trends in the Development of Higher Education: Monograph. Tomsk: Tomsk Polytechnic University, p. 404.

[12] Burlakova, I. I. (2013). The Quality of Education and its Assessment in Higher Education. Theory and Methodology: Monograph. Moscow: New Russian University, p. 112.

[13] Huimin Ma, Xiang Wu, Li Yan, Han Huang, Han Wub, Jie Xiongb, Jinlong Zhanga. (2018) Strategic Plan of "Made in China 2025" and Its Implementation. Analysing the Impacts of Industry 4.0 in Modern Business Environments. 2018. Page 1-23.

[14] Malyavin, V. V. (2005) China Managed. Good Old Management. Moscow: Europe, pp. 10-18.

[15] Kalita, V.V. and Vinichuk, N. V. (2014). "The Image of "Typical Russian" in the Representation of Chinese and Russian Students". Humanitarian Studies in Eastern Siberia and the Far East, issue 1, pp. 37-41.

[16] Popkova, E. B. (2013). Inculturation of Foreign Students in the Russian High School: Institutional Conditions and the Main Stages: On an Example of SRSTU (NPI). (Thesis for PhD in Sociology, Rostov-on-Don, 2013)

[17] Raspetova, S. Y. (2011). Modern Cultural Strategies of the People's Republic of China in the Practice of International Interaction. (Thesis for PhD in Philosophy, Moscow State linguistic university, 2011). 
[18] Grebennikova, I. A. (2010). Pedagogical Support of Adaptation of Foreign Students in a Russian University: On the Example of Chinese students. (Thesis for PhD in Pedagogical Science, Birobidzhan, 2010).

[19] Danilenko, O. I., Li, T. and Xu, I. (2015). Adaptation of Chinese Students at Different Stages of Study at Universities in Russia and China. In V.V. Kalita (Ed.) Psychological Aspects of Intercultural Adaptation. Vladivostok: Dal'nauka, pp. 90-110.

[20] Dementieva, S. V. (2008). Russian Universities as a Mechanism for the Adaptation of Migrants (In the Context of Sociological and Philosophical Analysis). Bulletin of Tomsk Polytechnic University, vol. 6, issue 313, pp. 158-164.

[21] Li, W. and Baranova, I. I. (2017). Joint Educational Programs of Chinese and Russian Universities: Status, Trends and Prospects. Scientific and Technical Journal of SPbSPU. Humanities and Social Sciences, vol. 8, issue 1, pp. 134-141, doi: 10.18721 / Jhss.8116.

[22] Arefiev, A. L. and Sheregi, F. E. (2012). Education of Foreign Citizens in Higher Educational Institutions of the Russian Federation: A Statistical Compilation. Moscow: RUDN University, p. 124.

[23] Rogova T.M. (2013) Export of Russian university educational services. (Thesis for PhD in Economic Science, Rostov-on-Don, South Federal University, 2013). 